\title{
Impact of Ambient Temperature on Hyperthermia Induced by $( \pm)$ 3,4-Methylenedioxymethamphetamine in Rhesus Macaques
}

\author{
Stefani N Von Huben', Christopher C Lay', Rebecca D Crean', Sophia A Davis', Simon N Katner' \\ and Michael A Taffe*, I
}

'Molecular and Integrative Neurosciences Department, The Scripps Research Institute, La Jolla, CA, USA

\begin{abstract}
The ambient temperature $\left(T_{A}\right)$ under which rodents are exposed to $( \pm) 3,4$-methylenedioxymethamphetamine (MDMA) affects the direction and magnitude of the body temperature response, and the degree of hypo/hyperthermia generated in subjects can modify the severity of lasting brain changes in 'neurotoxicity' models. The thermoregulatory effects of MDMA have not been well described in nonhuman primates and it is unknown if $T_{A}$ has the potential to affect acute hyperthermia and therefore other lasting consequences of MDMA. The objective of this study was to determine if the temperature alteration produced by MDMA in nonhuman primates depends on $T_{A}$ as it does in rats and mice. Body temperature and spontaneous home cage activity were monitored continuously in six male rhesus monkeys via radiotelemetry. The subjects were challenged intramuscularly with $0.56-2.4 \mathrm{mg} / \mathrm{kg}( \pm)$ MDMA under each of three $T_{\mathrm{A}}$ conditions $\left(18,24\right.$, and $\left.30^{\circ} \mathrm{C}\right)$ in a randomized order. The temperature was significantly elevated following injection with all doses of MDMA under each ambient temperature. The magnitude of mean temperature change was $\sim 1{ }^{\circ} \mathrm{C}$ in most conditions suggesting a closely controlled thermoregulatory response in monkeys across a range of doses and ambient temperatures. Activity levels were generally suppressed by MDMA; however, a $50 \%$ increase over vehicle was observed after $0.56 \mathrm{MDMA}$ under the $30^{\circ} \mathrm{C}$ condition. It is concluded that MDMA produces a similar degree of hyperthermia in rhesus monkeys across a range of $T_{A}$ conditions that result in hypothermia or exaggerated hyperthermia in rodents. Monkey temperature responses to MDMA appear to be more similar to humans than to rodents and therefore the monkey may offer an improved model of effects related to MDMA-induced hyperthermia.

Neuropsychopharmacology (2007) 32, 673-68I. doi: I0.1038/sj.npp. I301078; published online 12 April 2006
\end{abstract}

Keywords: $( \pm)$ MDMA; Macaca mulatta; circadian; thermoregulation; serotonin

\section{INTRODUCTION}

The recreationally abused drug ( \pm )3,4-methylenedioxymethamphetamine (MDMA, 'Ecstasy') elevates body temperature in rats (Brown and Kiyatkin, 2004; Dafters, 1994; Malberg and Seiden, 1998), mice (Carvalho et al, 2002; Fantegrossi et al, 2003), guinea-pigs (Saadat et al, 2004), pigs (Fiege et al, 2003; Rosa-Neto et al, 2004), rabbits (Pedersen and Blessing, 2001), humans (Freedman et al, 2005), and rhesus macaques (Taffe et al, 2005). Sufficiently low ambient temperature conditions can prevent $( \pm)$ MDMA from inducing hyperthermia or even result in hypothermia in rodent models (Dafters, 1994; Gordon et al, 1991; Miller and O'Callaghan, 1994). Such effects can attenuate or prevent the occurrence of lasting changes, for

*Correspondence: Dr MA Taffe, Molecular and Integrative Neurosciences Department, SP30-2400, 10550 North Torrey Pines Road, The Scripps Research Institute, La Jolla, CA 92037, USA, Tel: + I 858 784 7228, Fax: + I 858784 7405, E-mail: mtaffe@scripps.edu Received 30 January 2006; revised 27 February 2006; accepted 6 March 2006

Online publication: 8 March 2006 at http:/www.acnp.org/citations/ Npp030806050609/default.pdf example, in central nervous system (CNS) serotonin (rat) or dopamine (mouse) function (Carvalho et al, 2002; Malberg and Seiden, 1998; Miller and O'Callaghan, 1994). Similarly, elevations of ambient temperature $\left(T_{\mathrm{A}}\right)$ appear to increase the magnitude of MDMA-induced hyperthermia and the severity of observed alterations to monoaminergic neurotransmission in rodents.

Investigations that have reported lasting reductions in CNS serotonin function (hereafter 'neurotoxicity' for brevity) associated with repeated MDMA dosing in nonhuman primates (Insel et al, 1989; Ricaurte et al, 1988; Slikker et al, 1988; Taffe et al, 2001) have been conducted across a range of $T_{\mathrm{A}}\left(\sim 21-27^{\circ} \mathrm{C}\right)$ under which rat temperature responses to MDMA convert from significant hypothermia to significant hyperthermia (Malberg and Seiden, 1998). Unfortunately, nonhuman primate neurotoxicity studies have not generally reported effects on body temperature; the single available report from such work suggests that $10 \mathrm{mg} / \mathrm{kg} S(+)$ MDMA reduces mean body temperature in chair restrained rhesus monkeys (Bowyer et al, 2003). The animals in that study were exposed to $S(+)$ MDMA under $T_{\mathrm{A}}$ of $21-22^{\circ} \mathrm{C}$; however, inspection of the individual data suggests that hyperthermia was 
observed in at least one of the individuals ( $\mathrm{J}$ Bowyer and $\mathrm{M}$ Paule, personal communication). Interestingly, the one animal with a clear hyperthermic response following the first $S(+)$ MDMA dose later exhibited the greatest degree of impairment on a learning task (Bowyer et al, 2003). This suggests that body temperature changes in monkeys may indeed be relevant for understanding the outcome of neurotoxic and other dose regimens.

We have recently established that an intramuscular dose of $1.7 \mathrm{mg} / \mathrm{kg}$ of $( \pm) \mathrm{MDMA}$, or either enantiomer, administered under $T_{\mathrm{A}}$ of $23-24^{\circ} \mathrm{C}$ in unrestrained rhesus monkeys elevates body temperature without significant increases in locomotor activity (Taffe et al, 2005). Interestingly, Freedman et al (2005) have shown that body temperature is elevated in human volunteers after $2.0 \mathrm{mg} / \mathrm{kg}( \pm)$ MDMA per os and that this effect is similar under $T_{\mathrm{A}}$ of 18 or $30^{\circ} \mathrm{C}$. The present study was designed to evaluate the impact of ambient temperature on thermoregulatory disruption produced by a recreational range of doses of $( \pm)$ MDMA in rhesus monkeys. The hypothesis to be tested was that this larger-bodied laboratory species would be insensitive to the effects of ambient temperature as are humans (Freedman et al, 2005) and therefore differ qualitatively from the rat (Malberg and Seiden, 1998).

\section{MATERIALS AND METHODS}

\section{Animals}

Six male rhesus monkeys (Macaca mulatta; Chinese origin) participated in this study. Animals were 5 years of age, weighed $7.8-10.4 \mathrm{~kg}$ at the start of the study, and exhibited body condition scores (Clingerman and Summers, 2005) of 2.0-2.5 out of 5 at the nearest quarterly exam. Daily chow (Lab Diet 5038, PMI Nutrition International; $3.22 \mathrm{kcal}$ of metabolizable energy (ME) per gram) allocations were determined by a power function (Taffe, 2004a, b) fit to data provided in a National Research Council recommendation (NRC/NAS, 2003) and modified individually by the veterinary weight management plan. Daily chow ranged from 215 to $254 \mathrm{~g} /$ day for the animals in this study. The animals' normal diet was supplemented with fruit or vegetables 7 days/week and water was available ad libitum in the home cage at all times. Animals on this study had previously been immobilized with ketamine $(5-20 \mathrm{mg} / \mathrm{kg})$ no less than semiannually for purposes of routine care and some experimental procedures. Animals also had various acute exposures to scopolamine, raclopride, methylphenidate, SCH23390, $\Delta^{9}$-THC, nicotine, and mecamylamine in behavioral pharmacological studies. No experimental drug treatments had been administered for a minimum of 1 year before the start of telemetry investigations. All protocols were approved by the Institutional Animal Care and Use Committee of The Scripps Research Institute. The United States National Institutes of Health guidelines for laboratory animal care (Clark et al, 1996) were followed, save the IACUC-approved elevation of ambient temperature outside the Guide-recommended range for this experiment. Four additional individuals not on the relevant protocol remained in the room for the ambient temperature studies by decision of the Attending Veterinarian following consideration of all aspects of animal well-being. These latter four animals had previously participated in a prior series of challenges with MDMA encompassing no more than eight doses of racemic MDMA or either enantiomer, administered at a dose of $1.7 \mathrm{mg} / \mathrm{kg}$, generally intramuscularly but at least once each p.o., at 1- to 2-week intervals (Taffe et al, 2005).

\section{Apparatus}

Radio telemetric transmitters (TA10TA-D70; Transoma Medical/Data Sciences International; Arden Hills, MN, USA) were implanted subcutaneously in the flank. The surgical protocol was adapted from the manufacturer's surgical manual and implantation was conducted by, or under supervision of, the TSRI veterinary staff using sterile techniques. Temperature and gross locomotor activity recordings were obtained continuously via an in-cage receiver and recorded on a $5 \mathrm{~min}$ sample interval basis by the controlling computer. The system requires the animal to move across approximately half the cage width to record an activity 'count'. Ambient room temperature was also recorded by the system via a thermometer mounted near the top of the housing room.

\section{Drug Challenge Studies}

For these studies, $0.0,0.56,1.0,1.78$, or $2.4 \mathrm{mg} / \mathrm{kg}$ of $( \pm) 3,4$ methylenedioxymethamphetamine $\mathrm{HCl}$ (MDMA) was administered intramuscularly in a volume of $0.1 \mathrm{ml} / \mathrm{kg}$ saline. $( \pm)$ MDMA was provided by the National Institute on Drug Abuse. Animals were injected via brief physical restraint using the moveable back of the home cage, a procedure to which they are well accustomed. All animals remained in the home cage for the duration of the study. The dose range were based on pill-content analyses suggesting $\sim 75-125 \mathrm{mg}$ MDMA per 'Ecstasy' pill, thus $1-1.78 \mathrm{mg} / \mathrm{kg}$ MDMA for a single pill taken by the standard $70 \mathrm{~kg}$ person but as much as $2.5 \mathrm{mg} / \mathrm{kg}$ in a $50 \mathrm{~kg}$ woman or as little as $0.83 \mathrm{mg} / \mathrm{kg}$ in a $90 \mathrm{~kg}$ man. The ambient room temperature was normally set at $24^{\circ} \mathrm{C}$ with a daily range of no more than $1^{\circ} \mathrm{C}$. For low and high $T_{\mathrm{A}}$ conditions, the room was set to 18 or $30^{\circ} \mathrm{C}$ at 0830 and restored to $24^{\circ} \mathrm{C}$ at 1630 . The room probe confirmed that $T_{\mathrm{A}}$ conditions were met within a variance of $\sim 1^{\circ} \mathrm{C}$. All challenges were administered at 1030 with active doses separated by at least 1 week in a pseudorandomized order.

\section{Data Analysis}

The temperature and activity data were collected each $5 \mathrm{~min}$ and analysis time points were thereafter expressed as a moving average of three samples $(-5 \mathrm{~min}$, current,$+5 \mathrm{~min})$ for each $10 \mathrm{~min}$ time point. Two-way randomized block analysis of variance (ANOVA) was employed to evaluate acute treatment-related effects starting $10 \mathrm{~min}$ before injection (as the preinjection comparison) and continuing until 240 min postinjection (p.i.). This interval was selected for analysis because animals were fed chow and supplements after this interval, as under normal conditions. Thus, the two within-subjects factors for ANOVA were time relative to injection ( -10 to 240$)$ and ambient temperature condition $\left(18,24\right.$, and $\left.30^{\circ} \mathrm{C}\right)$; separate analyses were conducted for each drug dose. Telemetry data from the 
four additional animals in the housing room were being collected under a different protocol and were used here for additional comparisons. As these animals did not undergo differential treatment on the days of changed ambient temperature, observations were collapsed across four observations under a given ambient condition for each of these individuals. Significant main effects in the two-way ANOVAs were followed up with the Newman-Keuls post hoc procedure to evaluate all pairwise comparisons. Average temperature and summed activity counts for the interval $2 \mathrm{~h}$ p.i. were analyzed by one-way repeated measures ANOVA for each ambient temperature with a factor of drug treatment condition. Any significant main effects were followed with the Newman-Keuls post hoc procedure to evaluate all pairwise comparisons and the Dunnett post hoc test to determine differences from the vehicle condition. All statistical analyses were conducted using GB-STAT v7.0 for Windows (Dynamic Microsystems Inc., Silver Spring, MD, USA) and the criterion for significance in all tests was $p<0.05$.

\section{RESULTS}

The administration of $( \pm)$ MDMA resulted in an increase of subcutaneous body temperature under all treatment conditions (Figure 1). The effect was observed within 5-10 min after injection (the elevation of the ' 0 ' time point reflects

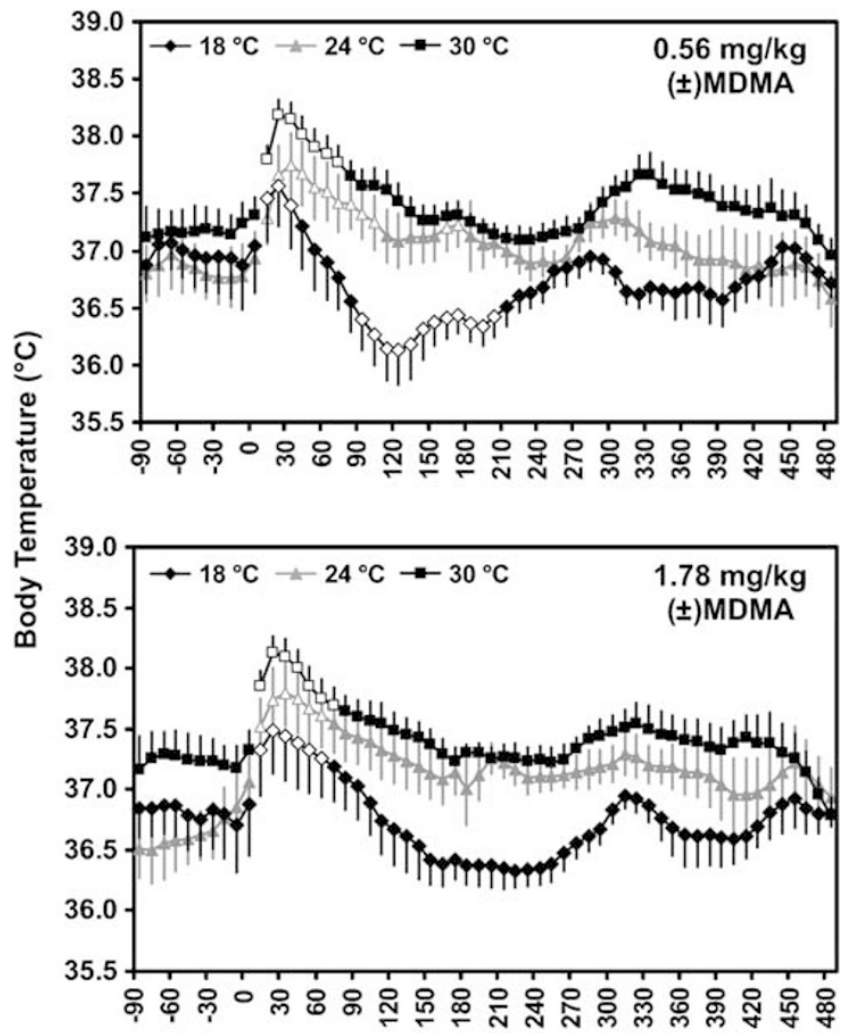

inevitable variability in the timing of injecting six animals relative to the computer sampling schedule as well as the moving average analysis) and animals reached a temperature peak about $20-40$ min p.i. Body temperature was relatively stable in the $90 \mathrm{~min}$ before injection in each of the altered $T_{\mathrm{A}}$ conditions with the warmest condition resulting in an average increase of about $0.5^{\circ} \mathrm{C}$ relative to the standard $T_{\mathrm{A}}$ condition. Effects of the low ambient temperature observed in the interval before injection differed from the standard condition less consistently.

Statistical analysis was conducted for each drug dose to confirm the impact of ( \pm )MDMA exposure at each of the ambient temperature conditions for the interval $-10 \mathrm{~min}$ through $240 \mathrm{~min}$ p.i. For the $0.56 \mathrm{mg} / \mathrm{kg}$ dose, the analysis confirmed a main effect of $T_{\mathrm{A}}$ condition $\left(\mathrm{F}_{2,10}=18.16\right.$; $p<0.001)$, of time p.i. $\left(\mathrm{F}_{25,125}=19.86 ; p<0.0001\right)$, and an interaction of factors $\left(\mathrm{F}_{50,250}=5.83 ; p<0.0001\right)$. The post hoc analysis further confirmed that temperature was significantly elevated relative to the preinjection baseline under $18^{\circ} \mathrm{C}$ (10-30 min p.i.), $24^{\circ} \mathrm{C}(10-100 \mathrm{~min}$ p.i.), and $30^{\circ} \mathrm{C}$ (10-70 min p.i.) conditions. Furthermore, temperature was significantly lower in the $18^{\circ} \mathrm{C} T_{\mathrm{A}}$ condition $40-210 \mathrm{~min}$ p.i. in comparison with the same time points in the $24^{\circ} \mathrm{C} T_{\mathrm{A}}$ condition and lower for time points $20-240 \mathrm{~min}$ p.i. in the $30^{\circ} \mathrm{C} T_{\mathrm{A}}$ condition. Temperature in the $30^{\circ} \mathrm{C} T_{\mathrm{A}}$ condition was reliably higher before injection and $10-20 \mathrm{~min}$ p.i. in comparison with the $24^{\circ} \mathrm{C} T_{\mathrm{A}}$ condition at any time point analyzed.
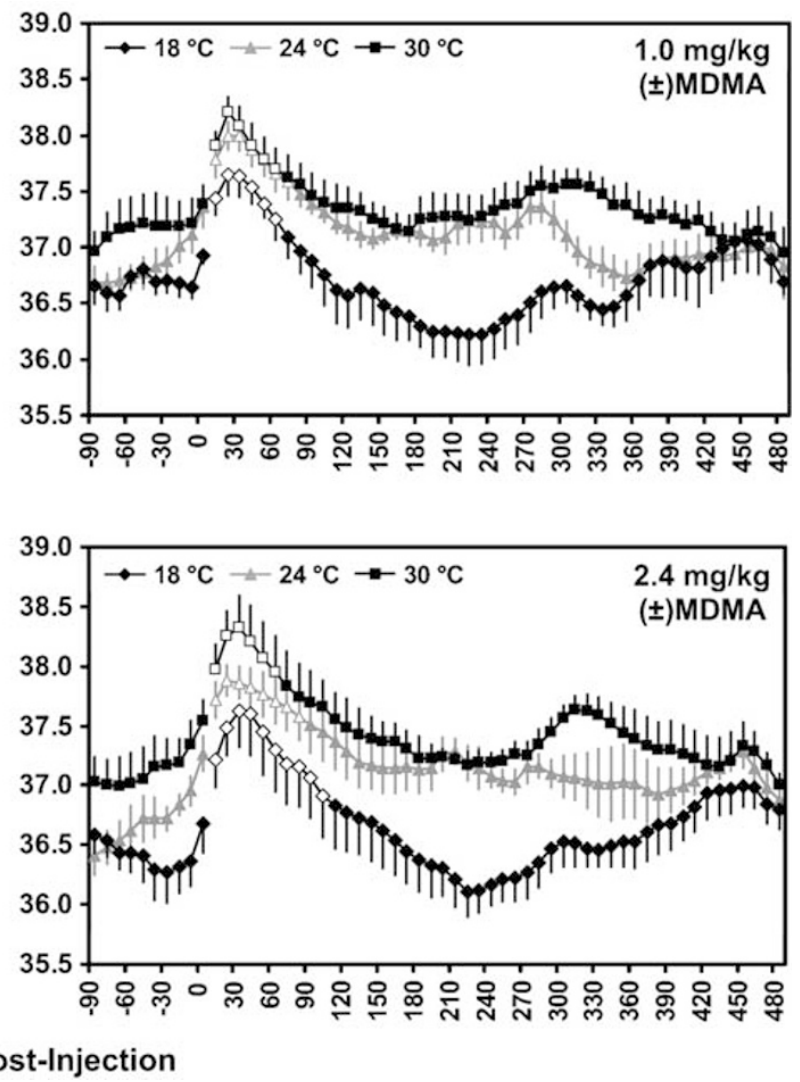

Figure I The mean ( $N=6$, bars indicate SEM) subcutaneous temperature values following acute challenge with four doses of ( \pm )MDMA under each of three ambient temperature conditions. The break in the series indicates the time of injection; the slight change at time ' $O$ ' reflects variation in injecting all six subjects relative to the computer sampling schedule and the moving average procedure; see Materials and methods. A significant difference from the time point preceding injection is indicated by the open symbols; additional significant differences are detailed in Results. 
For the $1.0 \mathrm{mg} / \mathrm{kg}$ dose, the analysis confirmed a main effect of $T_{\mathrm{A}}$ condition $\left(\mathrm{F}_{2,10}=40.54 ; p<0.0001\right)$, of time p.i. $\left(\mathrm{F}_{25,125}=46.56 ; p<0.0001\right)$, and an interaction of factors $\left(\mathrm{F}_{50,250}=2.26 ; p<0.0001\right)$. Post hoc analysis confirmed that temperature was significantly elevated relative to the preinjection baseline under $18^{\circ} \mathrm{C}\left(10-60 \mathrm{~min}\right.$ p.i.), $24^{\circ} \mathrm{C}$ (10-70 min p.i.), and $30^{\circ} \mathrm{C}(10-60 \mathrm{~min}$ p.i.) conditions, and that temperature was significantly lower in the $18^{\circ} \mathrm{C} T_{\mathrm{A}}$ condition before injection and 70-240 $\mathrm{min}$ p.i. in comparison with the same time points in the $24^{\circ} \mathrm{C} T_{\mathrm{A}}$ condition and lower for all time points except $30-60 \mathrm{~min}$ p.i. in the $30^{\circ} \mathrm{C}$ $T_{\mathrm{A}}$ condition. Temperature in the $24^{\circ} \mathrm{C} T_{\mathrm{A}}$ condition did not reliably differ from the $30^{\circ} \mathrm{C} T_{\mathrm{A}}$ condition at any time point analyzed.

For the $1.78 \mathrm{mg} / \mathrm{kg}$ dose, the analysis confirmed a main effect of $T_{\mathrm{A}}$ condition $\left(\mathrm{F}_{2,10}=20.95 ; p<0.001\right)$, of time p.i. $\left(\mathrm{F}_{25,125}=11.48 ; p<0.0001\right)$, and an interaction of factors $\left(\mathrm{F}_{50,250}=1.43 ; p<0.05\right)$. The post hoc test confirmed that temperature was significantly elevated relative to the preinjection baseline under $18^{\circ} \mathrm{C}\left(10-60 \mathrm{~min}\right.$ p.i.), $24^{\circ} \mathrm{C}$ (10-60 min p.i.), and $30^{\circ} \mathrm{C}(10-70 \mathrm{~min}$ p.i.) conditions. Temperature was significantly lower in the $18^{\circ} \mathrm{C} T_{\mathrm{A}}$ condition 110-240 min p.i. in comparison with the same time points in the $24^{\circ} \mathrm{C} T_{\mathrm{A}}$ condition and lower for time points $20-50$ and $80-240 \mathrm{~min}$ p.i. in the $30^{\circ} \mathrm{C} T_{\mathrm{A}}$ condition.
Temperature in the $24^{\circ} \mathrm{C} T_{\mathrm{A}}$ condition did not reliably differ from the $30^{\circ} \mathrm{C} T_{\mathrm{A}}$ condition at any time point analyzed.

For the $2.4 \mathrm{mg} / \mathrm{kg}$ dose, the analysis confirmed a main effect of $T_{\mathrm{A}}$ condition $\left(\mathrm{F}_{2,10}=13.23 ; p<0.01\right)$, of time p.i. $\left(\mathrm{F}_{25,125}=12.78 ; p<0.0001\right)$, and an interaction of factors $\left(\mathrm{F}_{50,250}=1.46 ; p<0.05\right)$. Temperature was significantly elevated relative to the preinjection baseline under $18^{\circ} \mathrm{C}$ (10-100 min p.i.), $24^{\circ} \mathrm{C}\left(10-80 \mathrm{~min}\right.$ p.i.), and $30^{\circ} \mathrm{C}(10-$ $60 \mathrm{~min}$ p.i.) conditions as confirmed with the post hoc analysis. Temperature was significantly lower in the $18^{\circ} \mathrm{C} T_{\mathrm{A}}$ condition for all time points except $10-150 \mathrm{~min}$ p.i. in comparison with the same time points in the $24^{\circ} \mathrm{C} T_{\mathrm{A}}$ condition and lower for all time points in comparison in the $30^{\circ} \mathrm{C} T_{\mathrm{A}}$ condition. Temperature in the $24^{\circ} \mathrm{C} T_{\mathrm{A}}$ condition did not reliably differ from the $30^{\circ} \mathrm{C} T_{\mathrm{A}}$ condition at any time point analyzed.

Intersubject heterogeneity was observed as illustrated in Figure 2 for the highest and lowest dose. Individual hyperthermic responses ranged from about $0.4-0.5^{\circ} \mathrm{C}$ over preinjection baseline to as much as $1.8-2.0^{\circ} \mathrm{C}$ over preinjection baseline. It is also apparent that individual animals exhibit a reasonable amount of consistency across $( \pm)$ MDMA dose and ambient temperature in terms of both the magnitude and duration of the temperature response.
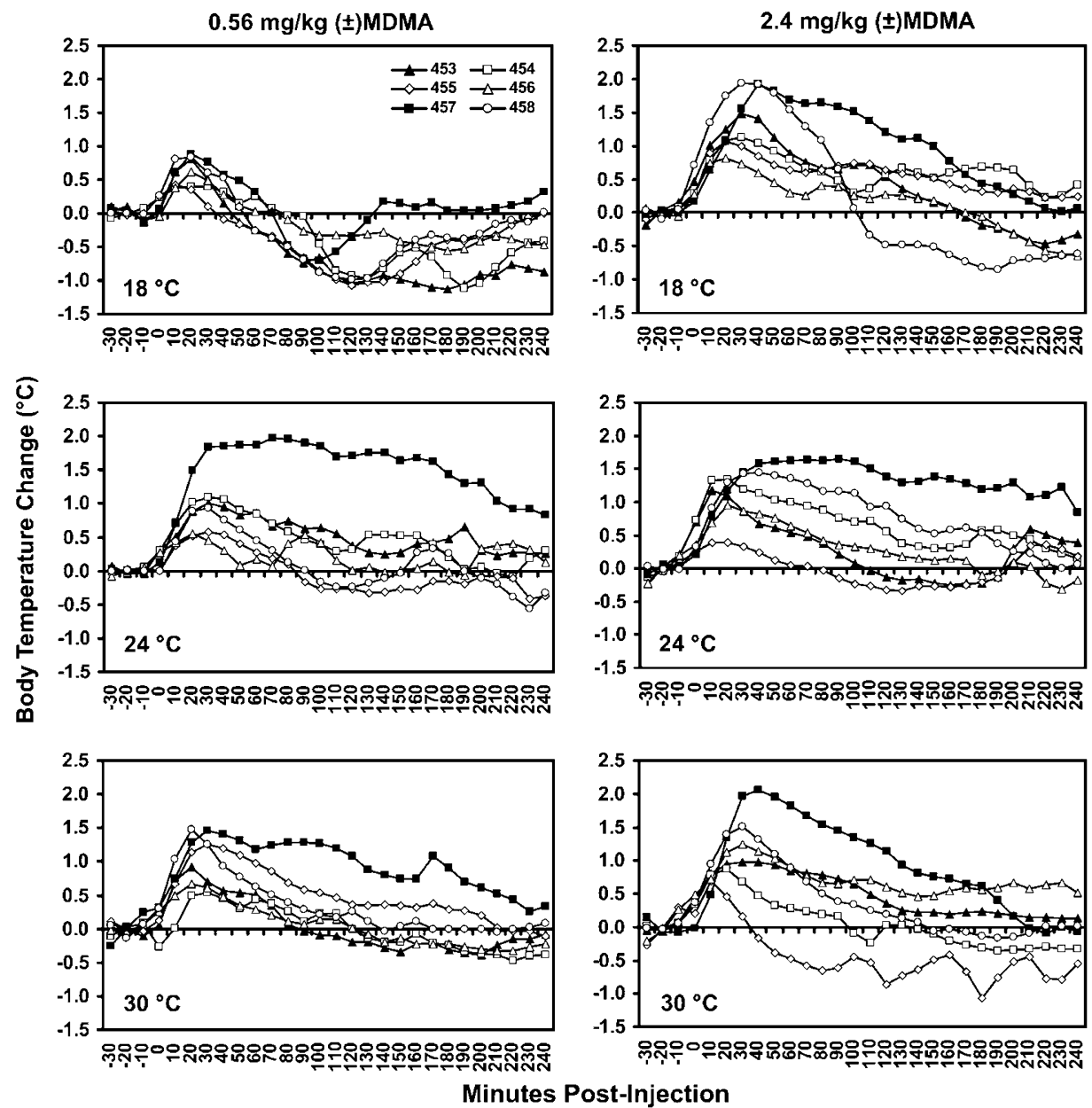

Figure 2 The individual subjects' subcutaneous temperatures following acute challenge with the lowest and highest doses of ( \pm )3,4-MDMA are depicted for each of three ambient temperatures. The data are represented as changes from the individuals' baseline temperature in degrees Celsius. 

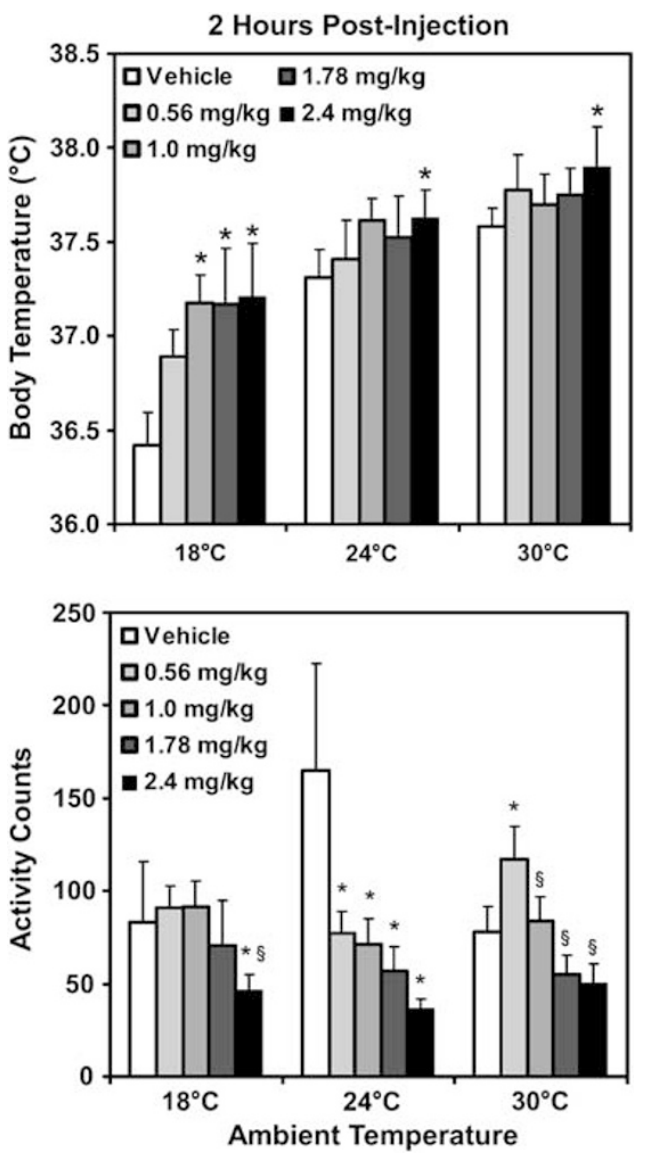

Figure 3 The mean $(N=6,+S E M)$ average body temperature (upper panel) and summed activity counts (lower panel) across the 2-h interval following injection of MDMA or vehicle under each of three ambient temperature conditions. A significant difference from vehicle is indicated by * and a significant difference from the $0.56 \mathrm{mg} / \mathrm{kg}$ dose is indicated by $\S$.

Average temperature in the interval 2-h after injection (Figure 3) was confirmed by significant main effects of drug treatment condition under the $18^{\circ} \mathrm{C} \quad T_{\mathrm{A}} \quad\left(\mathrm{F}_{4,36}=12.53\right.$; $p<0.0001)$, the $24^{\circ} \mathrm{C} T_{\mathrm{A}}\left(\mathrm{F}_{4,36}=3.23 ; p<0.05\right)$, and the $30^{\circ} \mathrm{C} T_{\mathrm{A}}\left(\mathrm{F}_{4,36}=5.42 ; p<0.01\right)$ conditions. Post hoc comparisons confirmed significant increases over vehicle for the $1.0-2.4 \mathrm{mg} / \mathrm{kg}$ doses at $18^{\circ} \mathrm{C} T_{\mathrm{A}}$ and for the $2.4 \mathrm{mg} / \mathrm{kg}$ dose at either $24^{\circ} \mathrm{C} T_{\mathrm{A}}$ or $30^{\circ} \mathrm{C} T_{\mathrm{A}}$. Activity patterns were highly consistent with our prior report (Taffe et al, 2005) with activity levels being highest at the time of injection and thereafter decreasing to low levels for up to $3 \mathrm{~h}$ after injection. These patterns were nearly identical across all treatment conditions, including vehicle. The summed activity counts did differ between conditions in the interval $2 \mathrm{~h}$ after injection (Figure 3 ) as confirmed by significant main effects of drug treatment condition under the $18^{\circ} \mathrm{C} T_{\mathrm{A}}$ $\left(\mathrm{F}_{4,36}=5.24 ; p<0.01\right)$, the $24^{\circ} \mathrm{C} T_{\mathrm{A}}\left(\mathrm{F}_{4,36}=3.74 ; p<0.05\right)$, and the $30^{\circ} \mathrm{C} T_{\mathrm{A}}\left(\mathrm{F}_{4,36}=13.53 ; p<0.0001\right)$ conditions. The post hoc tests confirmed that activity levels were significantly lower than vehicle or $0.56 \mathrm{mg} / \mathrm{kg}$ MDMA following $2.4 \mathrm{mg} / \mathrm{kg}$ MDMA under the $18^{\circ} \mathrm{C}$ condition, and lower than vehicle for all MDMA doses under the $24^{\circ} \mathrm{C} T_{\mathrm{A}}$ condition. Activity was significantly higher than vehicle and the three remaining MDMA doses after $0.56 \mathrm{mg} / \mathrm{kg}$ MDMA in the $30^{\circ} \mathrm{C} T_{\mathrm{A}}$ condition. Thus, locomotor activity most
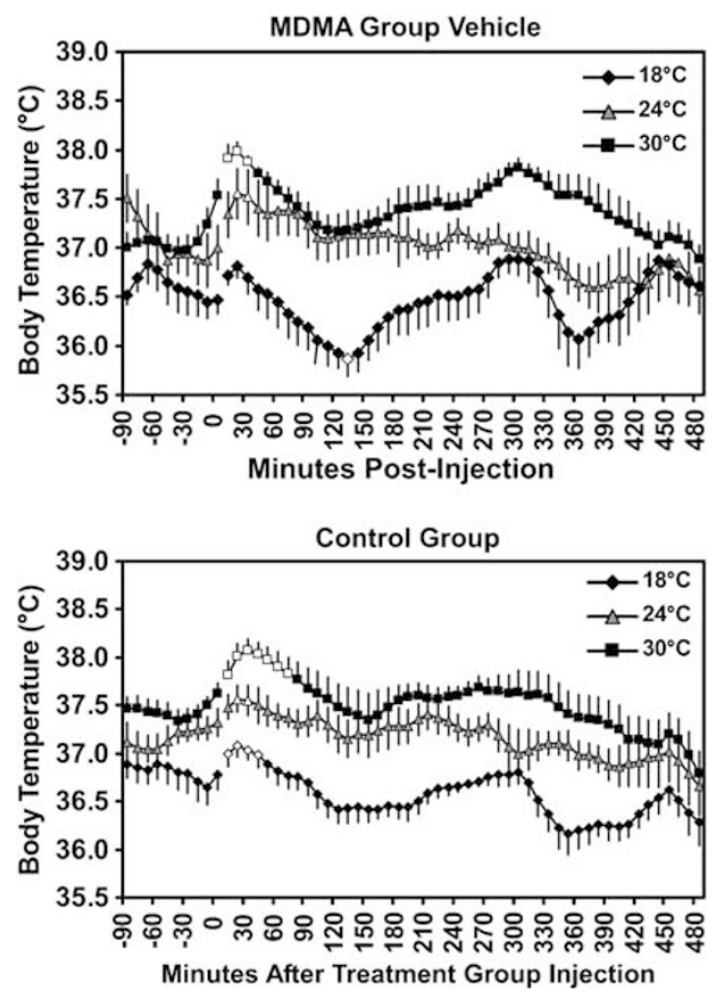

Figure 4 The mean subcutaneous temperature values following vehicle injection under three ambient temperature conditions for the experimental group $(N=6$, bars indicate SEM) are presented in the top panel. A significant difference from the time point preceding injection is indicated by the open symbols. The lower panel presents mean $(N=4$, bars indicate SEM) subcutaneous temperature under each ambient temperature for an untreated control group. The control group's data reflect grand averages of individual data averaged across four sessions for each ambient condition. These data are represented relative to the time of injection of the treatment group within the same housing room.

frequently decreased following MDMA administration; however, a slight increase in activity relative to vehicle was observed after the lowest dose of MDMA in the high ambient temperature condition.

Analysis of the vehicle data for the treated animals (Figure 4) confirmed a main effect of $T_{\mathrm{A}}$ condition $\left(\mathrm{F}_{2,10}=19.43 ; \quad p<0.001\right)$, of time p.i. $\quad\left(\mathrm{F}_{25,125}=7.17\right.$; $p<0.0001)$, and an interaction of factors $\left(\mathrm{F}_{50,250}=1.41\right.$; $p<0.05)$. The post hoc tests confirmed that temperature was significantly elevated relative to the preinjection baseline under $24^{\circ} \mathrm{C}\left(20-30 \mathrm{~min}\right.$ p.i.) and $30^{\circ} \mathrm{C}(10-30 \mathrm{~min}$ p.i.) conditions and significantly lower than preinjection in the $18^{\circ} \mathrm{C}$ condition at one time point $(130 \mathrm{~min})$ after injection. Analysis of the temperature data from the four uninjected control animals (Figure 4) confirmed a main effect of $T_{\mathrm{A}}$ condition $\left(\mathrm{F}_{2,6}=76.85 ; p<0.0001\right)$, of time p.i. $\left(\mathrm{F}_{25,75}=10.55 ; p<0.0001\right)$, and an interaction of factors $\left(\mathrm{F}_{50,150}=229 ; p<0.0001\right)$. Temperature in these animals was significantly elevated relative to the preinjection baseline under $18^{\circ} \mathrm{C}\left(10-40 \mathrm{~min}\right.$ p.i.), $24^{\circ} \mathrm{C}(20-30 \mathrm{~min}$ p.i. $)$, and $30^{\circ} \mathrm{C}$ (10-70 min p.i.) conditions as confirmed with the post hoc analysis.

Additional analysis was conducted on the activity data to compare the effect of vehicle or $2.4 \mathrm{mg} / \mathrm{kg}$ MDMA under the three ambient conditions for the interval $30 \mathrm{~min}$ before 

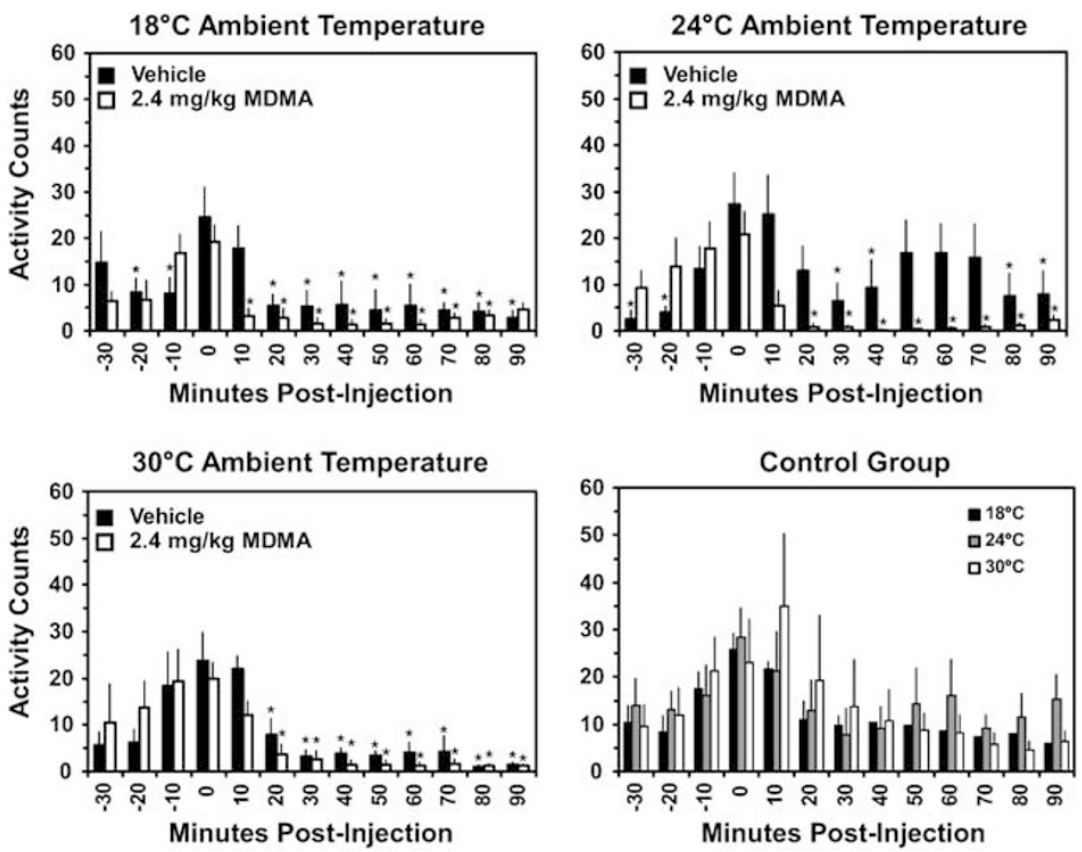

Figure 5 The mean $(N=6,+S E M)$ activity levels in the vehicle and $2.4 \mathrm{mg} / \mathrm{kg}$ MDMA conditions are presented for the experimental group under each of three ambient temperatures. The activity data for the control group are also presented; details are as described in the Figure 4 legend. Significant differences from the time of injection are indicated by *

injection until 90 min after injection (Figure 5). A three-way repeated measures ANOVA confirmed a significant main effect of time p.i. $\left(\mathrm{F}_{12,60}=25.22 ; p<0.0001\right)$ and an interaction of time p.i. with drug condition $\left(\mathrm{F}_{12,60}=3.90\right.$; $p<0.001)$. There were statistically unreliable trends for a main effect of drug condition $(p=0.080)$ and the interaction of ambient temperature with time p.i. $(p=0.059)$. In the $18^{\circ} \mathrm{C}$ condition, activity was significantly lower $10-80 \mathrm{~min}$ after MDMA and 20-90 min after vehicle, when compared with activity at the time of injection. Similar activity reductions relative to the time of injection were observed 20-90 min after MDMA and 30-40 min after vehicle in the $24^{\circ} \mathrm{C}$ ambient condition. Finally, activity was significantly lower 20-90 min after injection of either vehicle or MDMA in the $30^{\circ} \mathrm{C}$ ambient condition.

\section{DISCUSSION}

The results of this study show that $( \pm)$ MDMA causes an acute elevation of body temperature in rhesus macaques across an ambient temperature range of $18-30^{\circ} \mathrm{C}$. Thus, the monkey appears to respond similarly to humans (Freedman et al, 2005) and differently from rats, which become hypothermic after MDMA at $20^{\circ} \mathrm{C}$ ambient temperature (Malberg and Seiden, 1998). The overall implication of this work is that while smaller bodied mammals may be protected from MDMA-induced temperature elevations below $\sim 20^{\circ} \mathrm{C}$, this is unlikely to be the case for macaque monkeys or humans. These data also extend our initial study (Taffe et al, 2005) by demonstrating that the monkeys develop approximately equivalent changes in body temperature following a recreationally relevant range of MDMA doses $(0.56-2.4 \mathrm{mg} / \mathrm{kg})$. Reassuringly, the data suggest that comparisons made between the results of prior monkey neurotoxicity studies are unlikely to be substantially affected by the wide range of 'normal' ambient temperatures $\left(\sim 21-27^{\circ} \mathrm{C}\right)$ under which they have been conducted.

One important finding in this study is the identification of within-individual consistency and between-individual variability in the magnitude and duration of the temperature response. Such natural variation in phenotype may provide important clues to individual sensitivity. In human Ecstasy users, for example, threatening hyperthermia requiring emergency medical intervention apparently only occurs in a very small fraction of users. We have recently observed a situation in which emergency medical intervention was required to recover a monkey after an acute intramuscular dose of $2.4 \mathrm{mg} / \mathrm{kg} \quad S(+) M D M A$, which resulted in seizure and hyperthermia. This was unexpected because the animal had received acute doses of $2.4 \mathrm{mg} / \mathrm{kg}$ racemic and $R(-)$ MDMA as well as of $1.7 \mathrm{mg} / \mathrm{kg}$ racemic and both enantiomers of MDMA previously and no drug challenges had been administered for 3 months before this event (however, see Giorgi et al, 2005). The $\mathrm{LD}_{50}$ in rhesus monkeys has been estimated as $22 \mathrm{mg} / \mathrm{kg}( \pm)$ MDMA, i.v. (Hardman et al, 1973) and limited data suggest that a cumulative (over $6 \mathrm{~h}$ ) dose of $25.8 \mathrm{mg} / \mathrm{kg}( \pm$ )MDMA, p.o. was lethal in at least $33 \%$ of squirrel monkeys whereas a cumulative dose of $19.2 \mathrm{mg} / \mathrm{kg}$ was not (Mechan et al, 2006). As emergency medical events are not obviously related to dose in humans, nor in monkeys, some as yet unknown individual factors must be of primary significance. Individual differences in the monkey temperature response to MDMA may therefore provide important clues to the etiology of medical emergencies in human Ecstasy users. These findings also have important practical implications for experimental design in typically low ' $\mathrm{N}$ ' monkey studies. For example, Yuan et al (2006) found that a threatening hyperthermia is more likely to be evoked by 
methamphetamine under $33^{\circ} \mathrm{C}$ than $26^{\circ} \mathrm{C}$ ambient conditions. The study, however, employed a between-subjects design and the difference appeared to be attributable to aberrant responses from $2 / 4$ animals treated at $33^{\circ} \mathrm{C}$. The present data (Figure 2) suggest that it would be quite possible to accidentally assign animals of significantly different temperature phenotype to different treatment groups given pools of 6-8 subjects.

One interesting feature of the present data was the unique result of the lowest dose of MDMA administered at $18^{\circ} \mathrm{C}$. Although an acute elevation of temperature was observed until 30-40 min p.i., this was the only case in which temperature dropped significantly (and consistently; Figure 2) below baseline within a few hours of dosing. This pattern is similar to that reported for rat following $40 \mathrm{mg} / \mathrm{kg}$ ( \pm )MDMA at $20^{\circ} \mathrm{C} T_{\mathrm{A}}$ (Malberg and Seiden, 1998). Thus it is possible that consistent MDMA-induced hypothermia may occur in humans and non-human primates albeit under even lower ambient temperatures and/or with lower doses.

The activity data extend our prior report (Taffe et al, $2005)$ in confirming that $( \pm)$ MDMA tends to suppress activity levels in monkeys. This is fortuitous as an interpretive matter because the temperature response can be observed independent of skeletal muscle activity/heat generation. Therefore, the present model most likely reflects heat generation from stimulation of metabolic rate (Freedman et al, 2005) as opposed to skeletal muscle activation. In contrast, rodent models appear to indicate that locomotor increases are usually observed in concert with temperature increases although it should be appreciated that rodent studies have often been conducted without examination of diurnal cycle; thus, close comparisons of effects in lightvs dark-cycle MDMA administration may be necessary to clearly establish Order differences. Interestingly, the temperature responses in the vehicle condition for the experimental group, as well as for the control group, emphasize that even relatively small differences in activity profile, sustained over tens of minutes, can result in acute elevations of body temperature, which render interpretations of drug effects complex at best. This is apparent with even a casual inspection of telemetry data in treatment naïve animals, which is why we first designed the period of observation following drug challenge to be as devoid of room 'excitement' as possible (Taffe et al, 2005). Of even further interest was the observation that although the effect of MDMA on temperature did not appear to interact with $T_{\mathrm{A}}$, the effect of increased activity (Figure 5) on body temperature (Figure 4) did appear to interact with $T_{\mathrm{A}}$. Temperature effects of activity were smaller at low ambient conditions, whereas effects of active drug were not.

The present results also provide evidence regarding the response of thermoregulatory mechanisms to MDMA in the monkey. Subcutaneous body temperature data are not identical to 'core' body temperature but are likely closely correlated in the macaque. For this study, mean temperature before challenge was about $1^{\circ} \mathrm{C}$ lower than values reported for intraperitoneal temperature in Japanese (Takasu et al, 2002) and pigtail (MR Weed, personal communication) macaques; this was consistent with prior reports for subcutaneous temperature in cynomolgous (Almirall et al, 2001) and rhesus (Horn et al, 1998) macaques. The circadian patterns of temperature regulation appear highly similar between s.c. and i.p. studies in terms of the magnitude of temperature variation from day to night as well as the magnitude of individual temperature variation across intervals as short as $5-10 \mathrm{~min}$. In our recent studies, we have compared rectal temperatures (obtained under light ketamine anesthesia) with concurrent telemetric temperature values in 17 monkeys; multiple determinations are available for most animals. The s.c. values were $\sim 1-3^{\circ} \mathrm{C}$ lower than (immobilized) rectal temperature across animals but the temperature differential is consistent across determinations within animal. For comparison, the skin temperature of macaques is about $7^{\circ} \mathrm{C}$ lower than rectal temperature at $T_{\mathrm{A}}$ of $18^{\circ} \mathrm{C}$ and about $2.5^{\circ} \mathrm{C}$ lower than rectal temperature at $T_{\mathrm{A}}$ of $30^{\circ} \mathrm{C}$ (Johnson and Elizondo, 1979). Human skin temperature is about $4^{\circ} \mathrm{C}$ lower than core temperature at $18^{\circ} \mathrm{C}$ and about $1.5^{\circ} \mathrm{C}$ lower than core temperature at $30^{\circ} \mathrm{C}$ (Freedman et al, 2005). In contrast, the core temperature of humans, rhesus monkeys, and rats does not vary substantially across $18-30^{\circ} \mathrm{C} \quad T_{\mathrm{A}}$ conditions (Freedman et al, 2005; Johnson and Elizondo, 1979; Malberg and Seiden, 1998). A mean effect of only $\sim 0.5^{\circ} \mathrm{C}$, attributable to $T_{\mathrm{A}}$, was observed in the present study suggesting that s.c. temperature is only minimally influenced by ambient conditions.

The question of temperature probe location is potentially important because MDMA produces peripheral vasoconstriction. This effect can produce stable or lowered skin temperature at the same time as increased core temperature in rats and rabbits (Mechan et al, 2002; Pedersen and Blessing, 2001), which suggests that impairment of peripheral heat shedding is an important contributor to MDMA-associated hyperthermia (Mills et al, 2004), at least in small mammals. The vehicle data from the present study demonstrate that peripheral shedding of heat induced by muscular activity is indeed significantly affected across the 24 or $30^{\circ} \mathrm{C} T_{\mathrm{A}}$ range in monkeys. Such considerations predict that the effect of MDMA on subcutaneous temperature might potentially be biased upward under high, and downward under low, $T_{\mathrm{A}}$ conditions in comparison with 'core' temperature. In contrast to this prediction, the observed change in temperature over preinjection baseline in the present study was similar under all conditions in the monkeys. The mean peak change in temperature ranged from 0.9 to $1.1^{\circ} \mathrm{C}$ for all MDMA doses in the 24 or $30^{\circ} \mathrm{C} T_{\mathrm{A}}$ conditions. The mean changes in the low ambient condition were slightly more variable but ranged from $0.65^{\circ} \mathrm{C}(0.56 \mathrm{mg} / \mathrm{kg})$ to $1.3^{\circ} \mathrm{C}(2.4 \mathrm{mg} / \mathrm{kg})$, suggesting no consistent interaction with the ambient temperature. Interestingly, Freedman et al (2005) showed that despite an $\sim 2^{\circ} \mathrm{C}$ difference in skin temperature across $18-30^{\circ} \mathrm{C} T_{\mathrm{A}}$ conditions in humans, $( \pm)$ MDMA induced changes in the temperature of skin and core of approximately the same magnitude. Human peripheral thermoregulation by vasodilation/vasoconstriction and sweating appears to be independently mediated (Inoue et al, 1998; Schick et al, 2003). Freedman and colleagues found that sweating onset in humans is at a core temperature of $35.5^{\circ} \mathrm{C}$ and a skin temperature of $37^{\circ} \mathrm{C}$. In rhesus monkeys, sweating starts at a rectal temperature of $37.7^{\circ} \mathrm{C}$ and a skin temperature of $35.4^{\circ} \mathrm{C}$ (Johnson and Elizondo, 1974) but this threshold is markedly increased by $( \pm)$ MDMA (Freedman et al, 2005); the skin temperature appeared to 
stabilize immediately after the onset of sweating. In combination with the nearly identical magnitude of the MDMA effect on skin $v s$ core temperature, this suggests that cutaneous vascular changes may contribute little to thermoregulation under these conditions. The most important conclusion is that primates likely exhibit a more consistent and linear relationship between core, subcutaneous, and skin temperature following MDMA in comparison with rodents. A second conclusion is that it is critical for the comparison of preclinical models to consider the role of locomotor activity. Additional study of rodent models in which MDMA does not consistently elevate activity and monkey models where it does would be of significant interest.

In summary, this study determined that $( \pm)$ MDMA produces acute hyperthermia in non-human primates in ambient temperature conditions ranging from 18 to $30^{\circ} \mathrm{C}$. In this the monkey appears to be more similar to humans and less similar to rodents. The change in monkeys' temperature over baseline was of an equivalent magnitude from high to low ambient temperature conditions across a range of doses that are similar to human recreational, and proposed clinical, doses. Therefore, low ambient temperatures that are neuroprotective in rodents are unlikely to have similar effects in monkeys or humans. The present findings thus have important implications for the translation of animal studies to human situation including both the recreational and clinical use of MDMA.

\section{ACKNOWLEDGEMENTS}

This work was supported by USPHS Grant DA018418. This is publication \#17979-MIND from The Scripps Research Institute.

\section{REFERENCES}

Almirall H, Bautista V, Sanchez-Bahillo A, Trinidad-Herrero M (2001). Ultradian and circadian body temperature and activity rhythms in chronic MPTP treated monkeys. Neurophysiol Clin 31: 161-170.

Bowyer JF, Young JF, Slikker W, Itzak Y, Mayorga AJ, Newport GD et al (2003). Plasma levels of parent compound and metabolites after doses of either $d$-fenfluramine or $d$-3,4-methylenedioxymethamphetamine (MDMA) that produce long-term serotonergic alterations. Neurotoxicology 24: 379-390.

Brown PL, Kiyatkin EA (2004). Brain hyperthermia induced by MDMA (ecstasy): modulation by environmental conditions. Eur J Neurosci 20: 51-58.

Carvalho M, Carvalho F, Remiao F, de Lourdes Pereira M, Pires-das-Neves R, de Lourdes Bastos M (2002). Effect of 3,4-methylenedioxymethamphetamine ('ecstasy') on body temperature and liver antioxidant status in mice: influence of ambient temperature. Arch Toxicol 76: 166-172.

Clark JD, Baldwin RL, Bayne KA, Brown MJ, Gebhart GF, Gonder JC et al (1996). Guide for the Care and Use of Laboratory Animals. Institute of Laboratory Animal Resources, National Research Council: Washington, DC. pp 125.

Clingerman KJ, Summers L (2005). Development of a body condition scoring system for nonhuman primates using Macaca mulatta as a model. Lab Anim (NY) 34: 31-36.

Dafters RI (1994). Effect of ambient temperature on hyperthermia and hyperkinesis induced by 3,4-methylenedioxymethamphet- amine (MDMA or 'ecstasy') in rats. Psychopharmacology (Berl) 114: 505-508.

Fantegrossi WE, Godlewski T, Karabenick RL, Stephens JM, Ullrich $\mathrm{T}$, Rice KC et al (2003). Pharmacological characterization of the effects of 3,4-methylenedioxymethamphetamine ('ecstasy') and its enantiomers on lethality, core temperature, and locomotor activity in singly housed and crowded mice. Psychopharmacology (Berl) 166: 202-211.

Fiege M, Wappler F, Weisshorn R, Gerbershagen MU, Menge M, Schulte Am Esch J (2003). Induction of malignant hyperthermia in susceptible swine by 3,4-methylenedioxymethamphetamine ('ecstasy'). Anesthesiology 99: 1132-1136.

Freedman RR, Johanson CE, Tancer ME (2005). Thermoregulatory effects of 3,4-methylenedioxymethamphetamine (MDMA) in humans. Psychopharmacology (Berl) 183: 248-256.

Giorgi FS, Pizzanelli C, Ferrucci M, Lazzeri G, Faetti M, Giusiani M et al (2005). Previous exposure to (+/-) 3,4-methylenedioxymethamphetamine produces long-lasting alteration in limbic brain excitability measured by electroencephalogram spectrum analysis, brain metabolism and seizure susceptibility. Neuroscience 136: 43-53.

Gordon CJ, Watkinson WP, O'Callaghan JP, Miller DB (1991). Effects of 3,4-methylenedioxymethamphetamine on autonomic thermoregulatory responses of the rat. Pharmacol Biochem Behav 38: 339-344.

Hardman HF, Haavik CO, Seevers MH (1973). Relationship of the structure of mescaline and seven analogs to toxicity and behavior in five species of laboratory animals. Toxicol Appl Pharmacol 25: 299-309.

Horn TF, Huitron-Resendiz S, Weed MR, Henriksen SJ, Fox HS (1998). Early physiological abnormalities after simian immunodeficiency virus infection. Proc Natl Acad Sci USA 95: 1507215077.

Inoue Y, Shibasaki M, Hirata K, Araki T (1998). Relationship between skin blood flow and sweating rate, and age related regional differences. Eur J Appl Physiol Occup Physiol 79: 17-23.

Insel TR, Battaglia G, Johannessen JN, Marra S, De Souza EB (1989). 3,4-Methylenedioxymethamphetamine ('ecstasy') selectively destroys brain serotonin terminals in rhesus monkeys. J Pharmacol Exp Ther 249: 713-720.

Johnson GS, Elizondo RS (1974). Eccrine sweat gland in Macaca mulatta: physiology, histochemistry, and distribution. J Appl Physiol 37: 814-820.

Johnson GS, Elizondo RS (1979). Thermoregulation in Macaca mulatta: a thermal balance study. J Appl Physiol 46: 268-277.

Malberg JE, Seiden LS (1998). Small changes in ambient temperature cause large changes in 3,4-methylenedioxymethamphetamine (MDMA)-induced serotonin neurotoxicity and core body temperature in the rat. J Neurosci 18: 5086-5094.

Mechan A, Yuan J, Hatzidimitriou G, Irvine RJ, McCann UD, Ricaurte GA (2006). Pharmacokinetic profile of single and repeated oral doses of MDMA in squirrel monkeys: relationship to lasting effects on brain serotonin neurons. Neuropsychopharmacology 31: 339-350.

Mechan AO, Esteban B, O'Shea E, Elliott JM, Colado MI, Green AR (2002). The pharmacology of the acute hyperthermic response that follows administration of 3,4-methylenedioxymethamphetamine (MDMA, 'ecstasy') to rats. Br J Pharmacol 135: 170-180.

Miller DB, O'Callaghan JP (1994). Environment-, drug- and stressinduced alterations in body temperature affect the neurotoxicity of substituted amphetamines in the C57BL/6J mouse. $J$ Pharmacol Exp Ther 270: 752-760.

Mills EM, Rusyniak DE, Sprague JE (2004). The role of the sympathetic nervous system and uncoupling proteins in the thermogenesis induced by 3,4-methylenedioxymethamphetamine. J Mol Med 82: 787-799. 
NRC/NAS (2003). Nutrient Requirements of Nonhuman Primates: Second Revised Edition. National Research Council of The National Academy of Sciences: Washington, DC.

Pedersen NP, Blessing WW (2001). Cutaneous vasoconstriction contributes to hyperthermia induced by 3,4-methylenedioxymethamphetamine (ecstasy) in conscious rabbits. J Neurosci 21: 8648-8654.

Ricaurte GA, Forno LS, Wilson MA, DeLanney LE, Irwin I, Molliver ME et al (1988). 3,4-Methylenedioxymethamphetamine selectively damages central serotonergic neurons in nonhuman primates. JAMA 260: 51-55.

Rosa-Neto P, Olsen AK, Gjedde A, Watanabe $\mathrm{H}$, Cumming $\mathrm{P}$ (2004). MDMA-evoked changes in cerebral blood flow in living porcine brain: correlation with hyperthermia. Synapse 53: 214-221.

Saadat KS, Elliott JM, Colado MI, Green AR (2004). Hyperthermic and neurotoxic effect of 3,4-methylenedioxymethamphetamine (MDMA) in guinea pigs. Psychopharmacology (Berl) 173: 452-453.

Schick CH, Fronek K, Held A, Birklein F, Hohenberger W, Schmelz M (2003). Differential effects of surgical sympathetic block on sudomotor and vasoconstrictor function. Neurology 60: $1770-1776$.

Slikker Jr W, Ali SF, Scallet AC, Frith CH, Newport GD, Bailey JR (1988). Neurochemical and neurohistological alterations in the rat and monkey produced by orally administered methylenedioxymethamphetamine (MDMA). Toxicol Appl Pharmacol 94: 448-457.

Taffe MA (2004a). Effects of parametric feeding manipulations on behavioral performance in macaques. Physiol Behav 81: 59-70.

Taffe MA (2004b). Erratum: 'Effects of parametric feeding manipulations on behavioral performance in macaques'. Physiol Behav 82: 589.

Taffe MA, Lay CC, Von Huben SN, Davis SA, Crean RD, Katner SN (2005). Hyperthermia induced by 3,4-methylenedioxymethamphetamine in unrestrained rhesus monkeys. Drug Alcohol Depend, 10 November [E-pub ahead of print].

Taffe MA, Weed MR, Davis S, Huitron-Resendiz S, Schroeder R, Parsons LH et al (2001). Functional consequences of repeated (+/-)3,4-methylenedioxymethamphetamine (MDMA) treatment in rhesus monkeys. Neuropsychopharmacology 24: 230-239.

Takasu N, Nigi H, Tokura H (2002). Effects of diurnal bright/dim light intensity on circadian core temperature and activity rhythms in the Japanese macaque. Jpn J Physiol 52: 573-578.

Yuan J, Hatzidimitriou G, Suthar P, Mueller M, McCann U, Ricaurte G (2006). Relationship between temperature, dopaminergic neurotoxicity, and plasma drug concentrations in methamphetamine-treated squirrel monkeys. J Pharmacol Exp Ther 316: 1210-1218. 